\title{
INHIBITION OF THE FORMATION OF AMYLOID-LIKE FIBRILS USING HERBAL EXTRACTS
}

\author{
MÁrta Kotormán, ${ }^{1 *}$ Zita Kelemen, ${ }^{1}$ \\ Phanindra Babu Kasi ${ }^{1,2}$ and János NemCsóK ${ }^{3}$ \\ ${ }^{1}$ Department of Biochemistry and Molecular Biology, Faculty of Science and Informatics, \\ University of Szeged, Középfasor 52, H-6726 Szeged, Hungary \\ ${ }^{2}$ Doctoral School in Biology, Faculty of Science and Informatics, University of Szeged, \\ Szeged, Hungary \\ 3Department of Biology, Pedagogical Faculty, Selye János University, \\ Bratislavská cesta 3322, SK-94501 Komarno, Slovak Republic
}

(Received: January 16, 2018; accepted: March 19, 2018)

\begin{abstract}
We tested the amyloid fibril formation inhibitory effect of seven teas diluted in $55 \%$ ethanol at $\mathrm{pH} 7.0$ at a protein concentration of $0.15 \mathrm{mg} / \mathrm{ml} \alpha$-chymotrypsin. In the experiments we investigated the formation and inhibition of amyloid fibrils by turbidity measurements, aggregation kinetics experiments and Congo red binding assay. The results suggest that the different teas effectively inhibit the formation of amyloidlike fibrils. The two most potent inhibitors were peppermint and melilot, extracts which almost completely inhibited the formation of aggregates in 5-fold dilution. The inhibitory effect on the aggregation formation of melilot and peppermint extracts was concentration dependant. The extent of inhibition was found to be proportional with the total concentration of phenolic compounds.
\end{abstract}

Keywords: $\alpha$-Chymotrypsin - amyloid fibrils - melilot - peppermint - polyphenols

\section{INTRODUCTION}

There are two alternative highly organized forms of proteins: the unique functional native states and the generic amyloid state [6]. The structural knowledge of protein aggregation will greatly be expanded in the next decade [13]. The insoluble amyloid fibrils have high, $\beta$-sheet content [39]. The amyloid structure is composed of the cross-beta-sheet entity, which is an almost indefinitely repeating two-layered intermolecular beta-sheet motif [30]. Amyloid fibrils can be associated with a number of diseases $[5,16]$. We can meet with them in neurodegenerative diseases such as Alzheimer's, Parkinson's and Huntington's disease, as well as type II diabetes, and primary and secondary amyloidosis [25]. These disorders are becoming increasingly common in the modern world, primarily as a consequence of increasing life spans and changing lifestyles. Nowadays they affect some 500 million people worldwide [6]. It is important to know the structure of the proteins and the factors that influence the formation of amyloid fibrils for the possible healing and prevention of the diseases. The ability to form the amyloid state is more general than it was previously believed. The vast majority of proteins are capable of forming amyloid fibrils, because the

\footnotetext{
*Corresponding author; e-mail address: kotorman@expbio.bio.u-szeged.hu
} 
property of the peptide backbones of polypeptide chains determine the process. Thus, we can gather information about the formation of amyloid fibrils, even about proteins that are not related to the proteins involved in the disease [18].

Drinking tea is an ancient habit; legends from India and China indicate that it started about 5,000 years ago [27]. In recent years, an increasing amount of research has focused on natural phenols/polyphenols found in many foods as important molecules for their beneficial effects against ageing and age-related pathological conditions [35]. Phenolic compounds including phenolic acids, flavonoids and proanthocyanidins are widely distributed in plants. Herbs are a source of dietary polyphenols [40]. The investigated herbal teas prepared from peppermint, melilot and sage delivered polyphenols in high amounts [7]. Among the constituents of tea polyphenols, catechins constitute about $30-42 \%$ of the dry weight. Epigallocatechin gallate is the major fraction of catechins [22]. It has been proved that epigallocatechin gallate bypasses the blood-brain barrier [2]. Epigallocatechin inhibited lysozyme fibrillation [20]. Studies by He et al. [11] have indicated that tea catechin polyphenols convert preformed lysozyme fibrils to amorphous aggregates. Studies by Kamihira-Ishijima et al. [15] have suggested that tea catechins specifically inhibit the early stages of islet amyloid polypeptide fragment (IAPP22-27) amyloid fibril formation to form amyloid nuclei by interacting with the unstructured peptide and that this inhibition mechanism is of great therapeutic value, because stabilization of the native state could delay the pathogenesis of amyloid diseases, and also the toxicity of the small oligomer (protofibril) is reported to be greater than that of the mature fibril. Studies also show that catechins may prevent the formation of amyloid- $\beta$ plaques and enhance cognitive functions, and thus may be useful in treating patients suffering of have Alzheimer's disease or dementia [8]. Quercetin, one of the most important natural polyphenols, dose-dependently inhibited amyloid formation of bovine insulin [37]. Gallic acid is one of the simplest biophenol found in many plants, including black and green tea, which effectively inhibited insulin amyloid fibril formation by changing the conformational transition of $\alpha$-helix/ $\beta$-sheet. The precise mechanism of action is not clear while the proposed mechanism suggested that the aromatic moiety of gallic acid might disturb the aromatic interactions involved in the insulin fibrillization. Polyhydroxy groups might have formed hydrogen bonds by replacing water molecules with appropriate groups on the insulin surface and thus they protect the native structure $[14,26]$. It has been shown that gallic acid potentially inhibits the selfaggregation process of hen egg white lysozyme in a concentration dependent manner. The $o$-dihydroxy moiety of gallic acid is oxidized into quinone moiety. The quinone binds near the hydrophobic region of lysozyme and restricts hydrophobic exposure [19]. It has been shown that gallic acid passes into blood-brain barrier [12]. It has been demonstrated that resveratrol modulated the self-assembly of $\beta$-lactoglobulin by increasing its hydrophobic interactions [24]. A tea bag $(2 \mathrm{~g})$ of peppermint leaves could provide $c a$. $19 \%$ of caffeic derivatives and $77 \%$ of flavonoids (total polyphenols content of $88 \mathrm{mg}$ ) [29]. The polyphenols present in the melilot extract are caffeic acid derivatives. Among them, rosmarinic acid is the major polyphenol component [30]. Rosmarinic acid prevents fibrillation of tau protein [3]. The percentages of inhi- 
bition of trypsin amyloid-like fibril formation changed proportionately with the concentrations of total phenolic compounds [19].

In earlier experiments our group have shown that $\alpha$-chymotrypsin forms amyloidlike fibrils in $55 \%$ ethanol at $\mathrm{pH} 7.0$ [32].

\section{MATERIALS AND METHODS}

Bovine pancreas $\alpha$-chymotrypsin (EC 3.4.21.1, three times crystallized, lyophilized) was obtained from Sigma-Aldrich Kft. The specific activity of the enzyme was $51 \mathrm{U} /$ $\mathrm{mg}$ using N-benzoyl-L-tyrosine ethyl ester (BTEE) as substrate, at $\mathrm{pH} 7.8$ at $25^{\circ} \mathrm{C}$. Ethanol was manufactured by Molar Chemicals Kft. We used the leaves of the following teas: peppermint (Menthae piperitae folium), nettle (Urticae folium), medical sage (Salviae folium), melilot (Melissae folium), thornapple buds (Crataegi folium cum flore), yarrow (Millefolii herba) and chamomile (Matricariae flos) all produced and marketed by the Mecsek-Drog Kft. (Hungary).

\section{Preparation of water-soluble extracts from teas}

Fifteen $\mathrm{ml}$ water was boiled, then taken off the source of heat, and $200 \mathrm{mg}$ of tea was added to it immediately. The tea leaves were left to brew in the water for 15 min until it cooled down to room temperature. Next the liquid was centrifuged. We followed the above procedure with every different kind of tea. The supernatants were stored in the freezer until we started to use them. The supernatants were used for the measurements. The supernatants were diluted with distilled water prior to the measurements as required.

\section{Turbidity measurement}

Using a Cecil CE5501 spectrophotometer, the extinction change was monitored at $350 \mathrm{~nm}$. A $1 \mathrm{~cm}^{3}$ cuvette was used. Changes in turbidity were measured at $24{ }^{\circ} \mathrm{C}$ at $\mathrm{pH} 7.0$, in $55 \%$ ethanol/10 mM phosphate buffer, at a protein concentration of 0.15 $\mathrm{mg} / \mathrm{ml}$ after 24 hours incubation. Significance was determined by one-way analysis of variance (ANOVA).

\section{Aggregation kinetics measurements}

Aggregation kinetics experiments were performed in 55\% ethanol/10 mM phosphate buffer ( $\mathrm{pH} 7.0$ ) by monitoring the absorption of the samples at $350 \mathrm{~nm}$ during 1200 sec at $24{ }^{\circ} \mathrm{C}$ in the presence or absence of different concentrations of melilot extract. The protein concentration was $0.15 \mathrm{mg} / \mathrm{ml}$. 


\section{Determination of total phenolic content}

The total phenolic content of the herbal extracts was determined by the FolinCiocalteu method [35]. The samples were allowed to stay at room temperature for $120 \mathrm{~min}$, and the absorbance was measured at $765 \mathrm{~nm}$. The total phenolic content was calculated from the calibration curve, and the results were expressed as mg gallic acid equivalents (GAE) per 1 of spice extracts. The data presented are the average of three measurements. The data were presented as mean \pm standard error of mean (SEM) obtained from three independent measurements.

\section{Congo red binding measurements}

Congo red (CR) binding assays were performed in the presence of $5 \mathrm{mM}$ phosphate buffer ( $\mathrm{pH} 7.0$ ) and $150 \mathrm{mM} \mathrm{NaCl}$ at a $6.2 \mu \mathrm{M} \mathrm{CR}$ concentration. In $55 \%$ ethanol, we incubated the protein sample of $0.15 \mathrm{mg} / \mathrm{ml}$ concentration at $24{ }^{\circ} \mathrm{C}$ for 24 hours, and then $0.2 \mathrm{ml}$ was mixed with $0.8 \mathrm{ml}$ Congo red solution, and we started measuring spectra 15 minutes later. The extinction spectrum was adjusted to a wavelength range of 400-600 nm. A $1 \mathrm{~cm}^{3}$ cuvette was used.

\section{RESULTS}

\section{$\alpha$-Chymotrypsin aggregation}

The extracts of seven types of teas were studied during the examination of the inhibition of $\alpha$-chymotrypsin aggregation as follows: chamomile, medical sage, melilot, nettle, peppermint, thornapple buds and yarrow. The results can be seen in Figure 1,

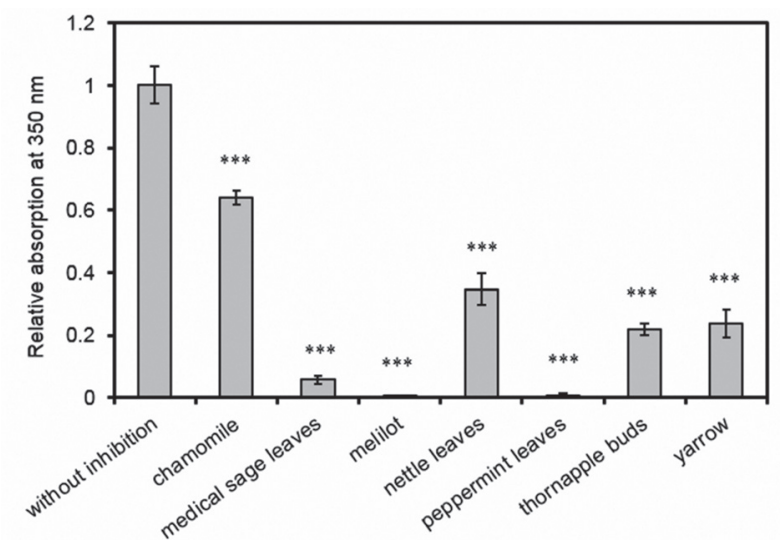

Fig. 1. Turbidity at $24{ }^{\circ} \mathrm{C}$ in $55 \%$ ethanol $/ 10 \mathrm{mM}$ phosphate buffer at $\mathrm{pH} 7.0,0.15 \mathrm{mg} / \mathrm{ml}$ protein concentration and tea diluted 5 times after $24 \mathrm{~h}$ incubation. All data were presented as mean \pm standard error of the mean (SEM) from three independent measurements. Significance was defined as $* * * P<0.001$ 
showing that the two most significant inhibitions were measured in the case of peppermint and melilot extracts. Melilot and peppermint extracts almost completely inhibited the formation of aggregates in 5 -fold dilution. Tea made from medical sage reduced the amount of aggregates to $6 \%$ compared to the control sample. In the case of thornapple buds tea $22 \%$, of yarrow $24 \%$, of nettle $35 \%$ and of chamomile tea $64 \%$ aggregate formation was observed in comparison to the non-tea control. All the teas induced significant difference in absorption at $350 \mathrm{~nm}$ compared to the sample with no tea in it. The P values were the following: chamomile, 0.0000242 , medical sage, 0.0000000291, melilot, 0.0000000187, nettle, 0.000000964, peppermint, 0.0000000195 , thornapple buds, 0.000000117 , and yarrow, 0.00000199 .

The effects of peppermint and melilot extract concentrations on aggregation were investigated. Our measurement results are shown in Figures 2 and 3. Their inhibitory

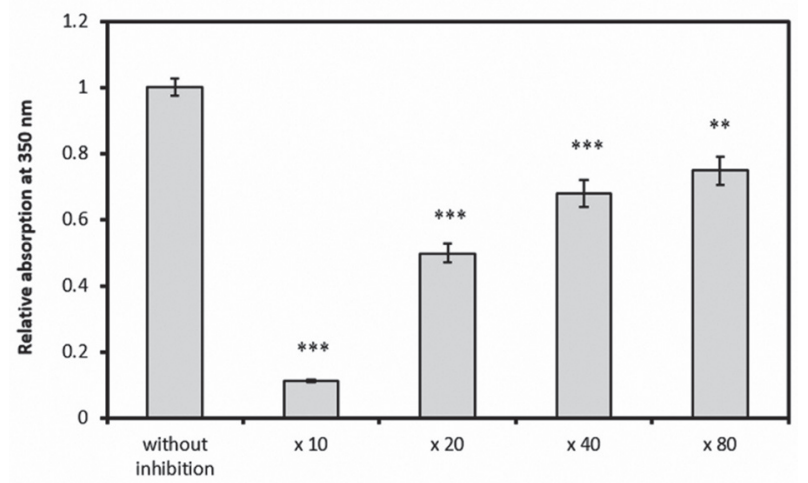

Fig. 2. Changes in turbidity in the presence of various concentration peppermint extract and without it at $24{ }^{\circ} \mathrm{C}$ in $55 \%$ ethanol/10 mM phosphate buffer at $\mathrm{pH} 7.0$ and at $0.15 \mathrm{mg} / \mathrm{ml}$ of $\alpha$-chymotrypsin after $24 \mathrm{~h}$ incubation. All data were presented as mean \pm standard error of the mean (SEM) from three independent measurements. Significance was defined as $* * * P<0.001$ and $* * P<0.01$

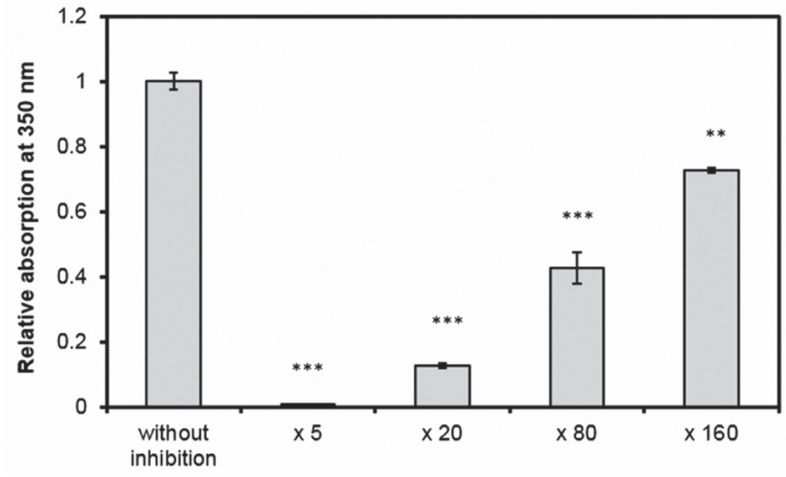

Fig. 3. Changes in turbidity in the presence of various concentration melilot extract and without it at $24{ }^{\circ} \mathrm{C}$ in $55 \%$ ethanol/10 mM phosphate buffer at $\mathrm{pH} 7.0$ and at $0.15 \mathrm{mg} / \mathrm{ml}$ of $\alpha$-chymotrypsin after $24 \mathrm{~h}$ incubation. All data were presented as mean \pm standard error of the mean (SEM) from three independent measurements. Significance was defined as $* * * P<0.001$ and $* * P<0.01$ 
effects have increased with increasing tea concentration. By the different dilutions, the $\mathrm{P}$ values were the following 0.0000000187 (melilot diluted 5 times), 0.0000429 (melilot diluted 20 times), 0.0000941 (melilot diluted 80 times), 0.001268 (melilot diluted 160 times) and 0.0000391 (peppermint diluted 10 times), 0.0000343 (peppermint diluted 20 times), 0.000393 (peppermint diluted 40 times), 0.006598 (peppermint diluted 80 times).

Aggregation of $\alpha$-chymotrypsin was monitored by following the absorption change at $350 \mathrm{~nm}$ for $1200 \mathrm{sec}$ in the presence or absence of different concentrations of melilot extract. Figure 4 shows the corresponding aggregation profiles of the protein.

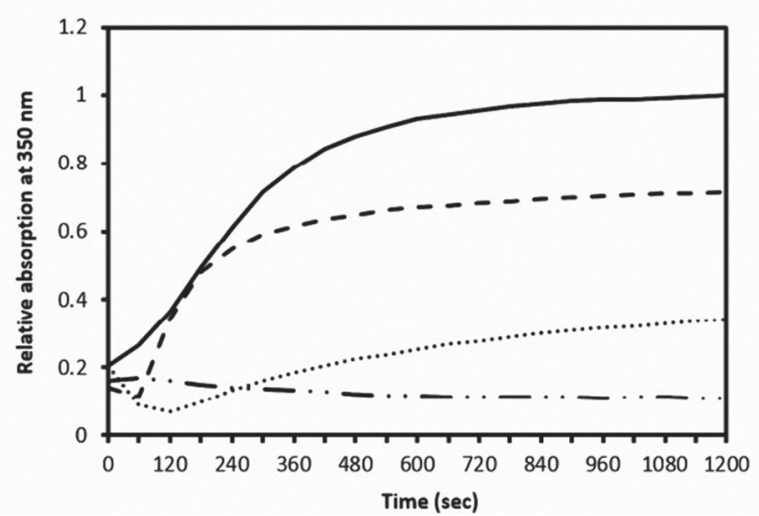

Fig. 4. Kinetics of aggregation of $\alpha$-chymotrypsin without melilot extract (solid line) in $55 \%$ ethanol/10 $\mathrm{mM}$ phosphate buffer at $\mathrm{pH} 7.0$, or in the presence of melilot extract diluted 160- (dashed line), 80(dotted line), or 20-fold (dotted-dashed line), monitored via the time-dependent increase of absorption at $350 \mathrm{~nm}$, at $0.15 \mathrm{mg} / \mathrm{ml}$ protein concentration

The final absorption at $350 \mathrm{~nm}$ decreased while the concentration of melilot extract increased. It demonstrates that the inhibition of $\alpha$-chymotrypsin aggregation by melilot extract is concentration dependent.

\section{Total phenol contents}

We calculated the percentage of inhibition of aggregation based on turbidity measurements. The total concentration of phenolic compounds of all herbal extracts was measured. The total concentrations of phenolic compounds of different herbal extracts ranged from 161.7 to $926.7 \mathrm{mg}$ GAE/l (Fig. 5). The calculated Pearson's correlation coefficient values $(r)$, was found to be between 0.5361 and 0.9999 . The extent of inhibition was proportional to the total concentration of phenolic compounds. 


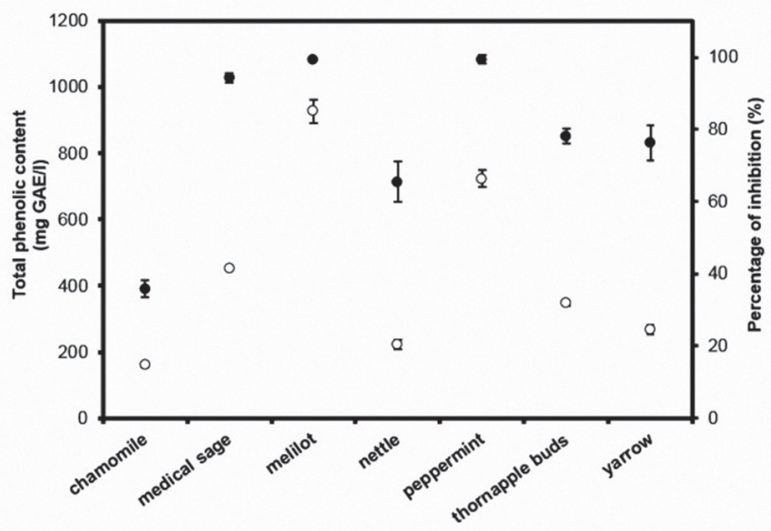

Fig. 5. The change in percentage of inhibition with the total phenolic content. Percentage of inhibition in $55 \%$ ethanol $(\bullet)$ and total phenolic content (o). Herbal extracts were diluted $\times 5$. Protein concentration was $0.15 \mathrm{mg} / \mathrm{ml}$. All data were presented as mean \pm standard error of the mean (SEM) from three independent measurements
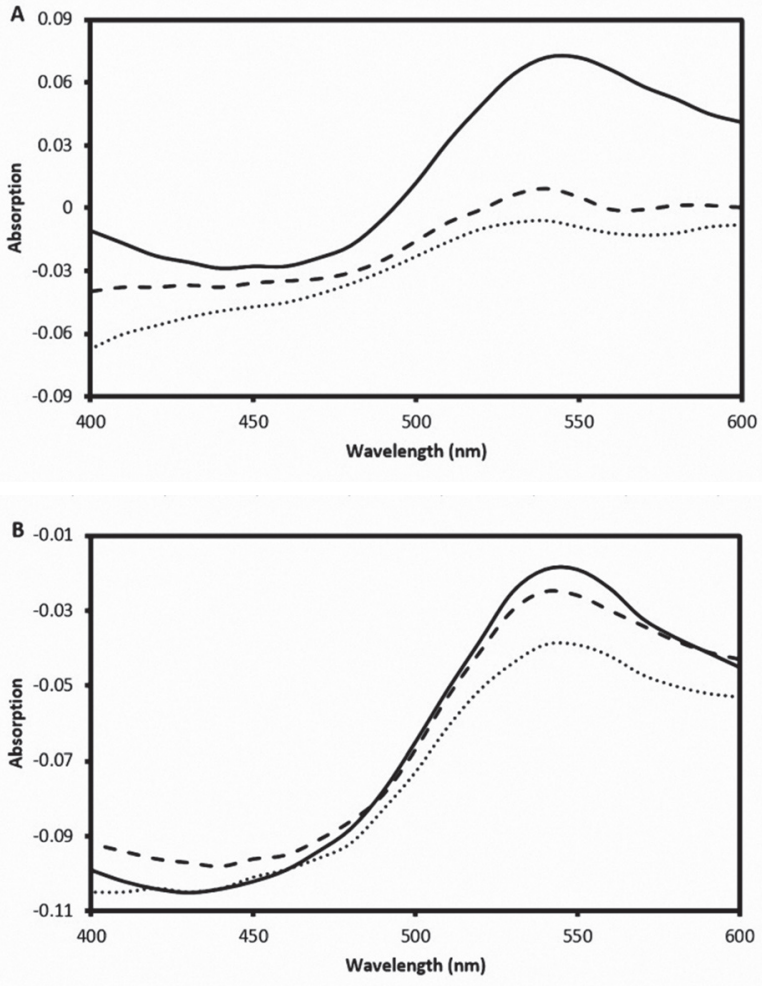

Fig. 6. CR differential spectra. Without melilot extract (solid line), in the presence of melilot extract in 50 -fold dilution (dashed line), melilot in 20-fold dilution (dotted line) (A), Without caffeic acid (solid line), $0.75 \mathrm{mM}$ caffeic acid (dashed line), $1.5 \mathrm{mM}$ caffeic acid (dotted line) (B) 


\section{Congo red binding}

CR differential spectra are shown in Fig. 6. This graphs were obtained by subtracting $\alpha$-chymotrypsin and CR spectra from the spectrum of $\alpha$-chymotrypsin $+\mathrm{CR}$ dye. These differential spectra demonstrated the spectral changes well. The results suggested a significant inhibition of $\alpha$-chymotrypsin aggregation by melilot extract. The inhibitory activity of melilot extract on fibril formation depends on concentration (Fig. 6A). We also investigated the efficiency of a specific compound, caffeic acid, as positive control. Our results indicated that the degree of inhibition of amyloid fibril formation is proportional to the concentration of caffeic acid used (Fig. 6B).

\section{DISCUSSION}

The turbidity measurement was used as an indication of the degree of aggregation. Although the sensitivity of the turbidity method is low, it can be a good tool when larger aggregates are formed $[21,26]$. Fuentes et al. also showed results in which peppermint proved to be a good islet amyloid polypeptide amyloid inhibitor [9]. Melilot contains coumarin [33]. Coumarin analogs were identified as novel inhibitors of amyloid $\beta$ aggregation [31].

For the detection of amyloid fibrils, CR diazo dye was used. CR is a well-known amyloid specific dye, which upon binding with the amyloid exhibits increase in absorption with a characteristic red shift [2]. CR specifically binds against $\beta$-pleated sheet conformation, and does not bind to the proteins with shorter $\beta$-pleated structures [21]. If the fibrils are present in the sample, and CR dye is added, the absorption maximum is displaced from $490 \mathrm{~nm}$ to $510 \mathrm{~nm}$. The advantage of CR staining compared with other amyloid fibrillation detection methods is that it is relatively quick and simple to use. Only a spectrophotometer is needed, and no radioactive labeling or expensive reagents are required for its application [15].

\section{ACKNOWLEDGEMENT}

This work was supported by project EFOP-3.6.1-16-2016-00008.

\section{REFERENCES}

1. Alexa, E., Danciu, C., Radulov, I., Obistioiu, D., Sumalan, R. M., Morar, A., Dehelean, C. A. (2018) Phytochemical screening and biologica activity of Mentha $\times$ piperita L. and Lavandula angustifolia Mill. extracts. Anal. Cell. Pathol. (Amst). 2018, 2678924.

2. Cascella, M., Bimonte, S., Muzio, M. R., Schiavone, V., Cuomo, A. (2017) The efficacy of Epigallocatechin-3-gallate (green tea) in the treatment of Alzheimer's disease: an overview of preclinical studies and translational perspectives in clinical practice. Infect. Agent. Cancer 12, 36.

3. Chaturvedi, S. K., Khan, J. M., Siddiqi, M. K., Alam, P., Khan, R. H. (2016) Comparative insight into surfactants mediated amyloidogenesis of lysozyme. Int. J. Biol. Macromol. 83, 315-325. 
4. Cornejo, A., Aguilar Sandoval, F., Caballero, L., Machuca, L., Muñoz, P., Caballero, J., Perry, G., Ardiles, A., Areche, C., Melo, F. (2017) Rosmarinic acid prevents fibrillization and diminishes vibrational modes associated to $\beta$ sheet in tau protein linked to Alzheimer's disease. J. Enzyme Inhib. Med. Chem. 32, 945-953.

5. Dobson, C. M. (2006) Protein aggregation and its consequences for human disease. Protein Pept Lett. 13, 219-227.

6. Dobson, C. M. (2017) The amyloid phenomenon and its links with human disease. Cold Spring Harb. Perspect. Biol. 9, pii: a023648.

7. Fecka, I., Turek, S. (2007) Determination of water-soluble polyphenolic compounds in commercial herbal teas from Lamiaceae: peppermint, melissa, and sage. J. Agric. Food Chem. 55, 10908-10917.

8. Fernando, W. M. A. D. B., Somaratne, G., Goozee, K. G., Williams, S., Singh, H., Martins, R. N. (2017) Diabetes and Alzheimer's disease: Can tea phytochemicals play a role in prevention? J. Alzheimers Dis. 59, 481-501.

9. Fuentes, A. L., Hennessy, K., Pascual, J., Pepe, N., Wang, I., Santiago, A., Chaggan, C., Martinez, J., Rivera, E., Cota, P., Cunha, C., Nogaj, L. A., Moffet, D. A. (2016) Identification of plant extracts that inhibit the formation of diabetes-linked IAPP Amyloid. J. Herb. Med. 6, 37-41.

10. Gazova, Z., Siposova, K., Kurin, E., Mucaji, P., Nagy, M. (2013) Amyloid aggregation of lysozyme: the synergy study of red wine polyphenols. Proteins 81, 994-1004.

11. He, J., Xing, Y. F., Huang, B., Zhang, Y. Z., Zeng, C. M. (2009) Tea catechins induce the conversion of preformed lysozyme amyloid fibrils to amorphous aggregates. J. Agric. Food Chem. 57, 1139111396.

12. Hsu, S. S., Chou, C. T., Liao, W. C., Shieh, P., Kuo, D. H., Kuo, C. C., Jan, C. R., Liang, W. Z. (2016) The effect of gallic acid on cytotoxicity, Ca2+ homeostasis and ROS production in DBTRG-05MG human glioblastoma cells and CTX TNA2 rat astrocytes. Chem. Biol. Interact. 252, 61-73.

13. Hu, H. Y. (2017) Structural aspects of protein aggregation. Protein Pept Lett. 24, 280.

14. Jayamani, J., Shanmugam, G. (2014) Gallic acid one of the components in many plant tissues, is a potential inhibitor for insulin amyloid fibril formation. Eur. J. Med. Chem. 85, 352-358.

15. Kamihira-Ishijima, M., Nakazawa, H., Kira, A., Naito, A., Nakayama, T. (2012) Inhibitory mechanism of pancreatic amyloid fibril formation: formation of the complex between tea catechins and the fragment of residues 22-27. Biochemistry 51, 10167-10174.

16. Khan, E., Mishra, S. K., Kumar, A. (2017) Emerging methods for structural analysis of protein aggregation. Protein Pept Lett. 24, 331-339.

17. Klunk, W. E., Jacob, R. F., Mason, R. P. (1999) Quantifying amyloid beta-peptide (Abeta) aggregation using the Congo red-Abeta (CR-abeta) spectrophotometric assay. Anal. Biochem. 266, 66-76.

18. Knowles, T. P., Vendruscolo, M., Dobson, C. M. (2014) The amyloid state and its association with protein misfolding diseases. Nat. Rev. Mol. Cell Biol. 15, 384-396.

19. Konar, M., Bag, S., Roy, P., Dasgupta, S. (2017) Gallic acid induced dose dependent inhibition of lysozyme fibrillation. Int. J. Biol. Macromol. 103, 1224-1231.

20. Kong, L. X. Zeng, C. M. (2017) Effects of seeding on lysozyme amyloid fibrillation in the presence of epigallocatechin and polyethylene glycol. Biochemistry (Mosc). 82, 156-167.

21. Kotormán, M., Kasi, P. B., Halász, L., Borics, A. (2017) Inhibition of amyloid-like fibril formation of trypsin by red wines. Protein Pept. Lett. 24, 466-470.

22. Kulandaivelu, K., Azad, M. A. K. (2016) Nanoencapsulated tea polyphenols as anticancer agent. Research Journal of Biotechnology 11, 92-101.

23. Kumar, E. K., Hague, N., Prabhu, N. P. (2017) Kinetics of protein fibril formation: Methods and mechanisms. Int. J. Biol. Macromol. 100, 3-10.

24. Ma, B., Zhang, F., Liu, Y., Xie, J., Wang, X. (2017) Resveratrol induces the conversion from amyloid to amorphous aggregation of $\beta$-lactoglobulin. Protein Pept Lett. 24, 1113-1119.

25. Nilsson, M. R. (2004) Techniques to study amyloid fibril formation in vitro. Methods 34, 151-160.

26. Omar, S. H. (2017) Biophenols pharmacology against the amyloidogenic activity in Alzheimer's disease. Biomed. Pharmacother. 89, 396-413. 
27. Peter, B., Bosze, S., Horvath, R. (2017) Biophysical characteristics of proteins and living cells exposed to the green tea polyphenol epigallocatechin-3-gallate (EGCg): review of recent advances from molecular mechanisms to nanomedicine and clinical trials. Eur. Biophys. J. 46, 1-24.

28. Radko, S. P., Khmeleva, S. A., Suprun, E. V., Kozin, S. A., Bodoev, N. V., Makarov, A. A., Archakov, A. I., Shumyantseva, V. V. (2015) Physico-chemical methods for studying amyloid- $\beta$ aggregation. Biomed. Khim. 9, 258-274.

29. Riachi, L. G., De Maria, C. A. (2015) Peppermint antioxidants revisited. Food Chem. 176, $72-81$.

30. Riek, R. (2017) The three-dimensional structures of amyloids. Cold Spring Harb. Perspect. Biol. 9 , pii: a023572.

31. Safra, J., Pospísilová, M., Honegr, J., Spilková, J. (2007) Determination of selected antioxidants in Melissae herba by isotachophoresis and capillary zone electrophoresis i the column-coupling configuration. J. Chromatogr. A1171, 124-132.

32. Simon, L. M., Laczkó, I., Demcsák, A., Tóth, D., Kotormán, M., Fülöp, L. (2012) The formation of amyloid-like fibrils of $\alpha$-chymotrypsin in different aqueous organic solvents. Protein Pept. Lett. 19, 544-550.

33. Soodi, M., Dashti, A., Hajimehdipoor, H., Akbari, S., Ataei, N. (2017) Melissa officinalis acidic fraction protects cultured cerebellar granule neurons against beta amyloid-induced apoptosis and oxidative stress. Cell J. 18, 556-564.

34. Soto-Ortega, D. D., Murphy, B. P., Gonzalez-Velasquez, F. J., Wilson, K. A., Xie, F., Wang, Q., Moss, M. A. (2011) Inhibition of amyloid- $\beta$ aggregation by coumarin analogs can be manipulated by functionalization of the aromatic center. Bioorg. Med. Chem. 19, 2596-2602.

35. Stefani, M., Rigacci, S. (2014) Beneficial properties of natural phenols: highlight on protection against pathological conditions associated with amyloid aggregation. Biofactors 40, 482-493.

36. Tamura, S., Warabi, Y., Matsubara, S. (2012) Severe liver dysfunction possibly caused by the combination of interferon beta-1b therapy and melilot (sweet clover) supplement. J. Clin. Pharm. Ther. 37, 724-725.

37. Wang, J. B., Wang, Y. M., Zeng, C. M. (2011) Quercetin inhibits amyloid fibrillation of bovine insulin and destabilizes preformed fibrils. Biochem. Biophys. Res. Commun. 415, 675-679.

38. Waterhouse, A. L. (2002) Determination of Total Phenolics. In: Wrolstad, R. E. (ed.) Current Protocols in Food Analytical Chemistry. John Wiley \& Sons, New York, pp. I1.1.1-I1.1.8.

39. Yiu, C. P. B., Chen, Y. W. (2017) From disorder to mis-order: Structural aspects of pathogenic oligomerization in conformational diseases. Protein Pept Lett. 24, 307-314.

40. Zhang, H., Tsao, R. (2016) Dietary polyphenols, oxidative stress and antioxidant and anti-inflammatory effects. Curr. Opin. Food Sci. 8, 33-42. 